Br Heart F 1985; 53: 585-6

Editorial

\title{
Chronic Mobitz type I second degree atrioventricular block Has its importance been underestimated?
}

\author{
RONALD W F CAMPBELL \\ From the University Department of Cardiology, Freeman Hospital, Newcastle upon Tyne
}

Second degree heart block traditionally is separated into subtypes considered to be clinically, pathologically, anatomically, prognostically, and therapeutically distinct. ${ }^{1-8}$

Mobitz type II block has been associated with an adverse prognosis through its progression to complete heart block with unstable and slow ventricular escape pacemakers. Pathological studies have indicated that the block is most usually in the His-fascicular system.

Mobitz type I block (Wenckebach block) has been regarded as much more benign. In young subjects, particularly those who are well trained, it can occur through excess vagal tone. ${ }^{9}$ In more elderly patients, disease of the atrioventricular node has been held responsible for the arrhythmia. In the event of complete atrioventricular block escape pacemakers are expected to be stable and to operate at a reasonable rate.

Shaw et al present data in the current issue of the journal ( $p$ 587) which challenge some of these long held concepts. In their figures, derived from up to 14 years of follow up in a selected but geographically contained population, three and five year survival rates in unpaced patients were similarly poor regardless of the type of second degree atrioventricular block. Based on this evidence, electrocardiographic features can no longer be used to separate high and low risk patients with second degree atrioventricular block. Their review of the prognostic data for type I block highlights the paucity of evidence on which current clinical practice is based and the ease with which authoritative opinion may be established. ${ }^{10}$

The findings of Shaw et al have important therapeutic implications. In their observational study, perma-

Requests for reprints to Dr R W F Campbell, Department of Cardiology, Freeman Hospital, Newcastle upon Tyne NE7 7DN. nent pacemaking was neither randomly nor systematically applied except as treatment for patients with major cardiac symptoms, particularly disturbances of consciousness. The significant prognostic advantage observed in paced patients leads the authors to conclude that patients with chronic type I second degree atrioventricular block "should be considered for pacemaker implantation on similar criteria to those adopted for higher degrees of block." Their observations of the results of this intervention refute a differential therapeutic approach to these subtypes of second degree atrioventricular block.

The authors, mindful of their observed $42 \%$ five year survival for unpaced patients with type I atrioventricular block, suggest that "in the absence of special circumstances" patients with this arrhythmia should be treated with pacemakers. The "special circumstances" are not specified, but the implication is that the policy for pacemaker implantation should be more liberal. We must, however, be cautious before adopting radical changes in clinical management. In the study as reported, the decision that a patient be paced or be left unpaced emerged as the most relevant prognostic factor, and the near normal life expectancy for paced patients emphasises the propriety of pacing for this group selected largely on the basis of symptoms. The study does not explore the question of whether or not the unpaced patients would have derived similar benefits from pacing. Although the results might merely support current indications for pacing in second degree atrioventricular block, the remarkably poor prognosis for unpaced patients, irrespective of the type of second degree block, forces reconsideration.

Adoption of a more aggressive pacing policy would have doubled the pacemaker insertion rate in the population reported in this study. If extrapolated to the United Kingdom, prophylactic pacing for Mobitz 
type I atrioventricular block might necessitate an extra 280 pacemaker insertions a year at a cost of $£ 165,000$. Have Shaw et al presented sufficiently secure evidence to support this approach? It is easy to procrastinate and to defer policy changes awaiting confirmation of controversial results. The long follow up required to assess the efficacy of intervention in this condition discourages, however, prospective investigation, and few other studies can be expected to be available within the next five or 10 years. Rather we must critically weigh this new evidence and acknowledge that Shaw et al present the most comprehensive information currently available for this patient population.

Scientists may await the definitive answer, but clinicians will be tempted to widen their indications for pacing in chronic second degree atrioventricular block. Fortunately, such an approach need not impede further scientific study. Implantation of a rate programmable VVI generator with a low backup pacing rate might preserve life in the event of asystole, while its activation would confirm its therapeutic value.

\section{References}

1 Wenckebach KF. Beiträge zur Kenntnis der menschlichen Herztätigkeit. Archiv fur Physiologie 1906; (suppl) 297-354.
2 Mobitz W. Uber den partiellen Herzblock. Zeitschrift für Klinische Medizin 1928; 107: 449-62.

3 Mobitz W. Uber die unvollständige Störung der Erregungsüber leitung zwischen Vorhof und Kammer des menschlichen Herzens. Zeitschrift fur die gesamte experimentelle Medizin 1924; 41: 180-237.

4 Hay J. Bradycardia and cardiac arrhythmia produced by depression of certain of the functions of the heart. Lancet 1906; 1: 139-43.

5 Lenègre J, Moreau P. Le block auriculo-ventriculaire chronique. Etude anatomique, clinique et histologique. Arch Mal Coeur 1963; 56: 867-88.

6 Lev M, Unger PN. The pathology of the conduction system in acquired heart disease. I. Severe atrioventricular block. Archives of Pathology 1955; 60: 502-29.

7 Strasberg B, Amat-y-Leon F, Dhingra RC, et al. Natural history of chronic second degree atrioventricular nodal block. Circulation 1981; 63: 1043-9.

8 Langendorf R, Pick A. Atrioventricular block, type II (Mobitz)-its nature and clinical significance. Circulation 1969; 38: 819-21.

9 Grossman M. Second degree heart block with Wenckebach phenomenon: its occurrence over a period of several years in a young healthy adult. Am Heart $\mathcal{F}$ 1958; 56: $607-10$.

10 Frye RL, Collins JJ, DeSanctis RW, et al. Guidelines for permanent cardiac pacemaker implantation, May 1984: A report of the Joint American College of Cardiology American Heart Association Task Force on Assessment of Cardiovascular Procedures. (Sub-committee on pacemaker implantation.) Circulation 1984; 70: 331A9A. 